\title{
Social Isolation Stress Induces Anxious-Depressive-Like Behavior and Alterations of Neuroplasticity-Related Genes in Adult Male Mice
}

\author{
Alessandro Ieraci, Alessandra Mallei, and Maurizio Popoli \\ Laboratorio di Neuropsicofarmacologia e Neurogenomica Funzionale, Dipartimento di Scienze Farmacologiche e Biomolecolari \\ e Centro di Eccellenza sulle Malattie Neurodegenerative, Università di Milano, Milano, Italy \\ Correspondence should be addressed to Alessandro Ieraci; alessandro.ieraci@unimi.it
}

Received 4 September 2015; Revised 4 November 2015; Accepted 11 November 2015

Academic Editor: Jordan Marrocco

Copyright (C) 2016 Alessandro Ieraci et al. This is an open access article distributed under the Creative Commons Attribution License, which permits unrestricted use, distribution, and reproduction in any medium, provided the original work is properly cited.

\begin{abstract}
Stress is a major risk factor in the onset of several neuropsychiatric disorders including anxiety and depression. Although several studies have shown that social isolation stress during postweaning period induces behavioral and brain molecular changes, the effects of social isolation on behavior during adulthood have been less characterized. Aim of this work was to investigate the relationship between the behavioral alterations and brain molecular changes induced by chronic social isolation stress in adult male mice. Plasma corticosterone levels and adrenal glands weight were also analyzed. Socially isolated (SI) mice showed higher locomotor activity, spent less time in the open field center, and displayed higher immobility time in the tail suspension test compared to group-housed (GH) mice. SI mice exhibited reduced plasma corticosterone levels and reduced difference between right and left adrenal glands. SI showed lower mRNA levels of the BDNF-7 splice variant, c-Fos, Arc, and Egr-1 in both hippocampus and prefrontal cortex compared to GH mice. Finally, SI mice exhibited selectively reduced mGluR1 and mGluR2 levels in the prefrontal cortex. Altogether, these results suggest that anxious- and depressive-like behavior induced by social isolation stress correlates with reduction of several neuroplasticity-related genes in the hippocampus and prefrontal cortex of adult male mice.
\end{abstract}

\section{Introduction}

Chronic stress is recognized to be a major risk factor for several psychiatric disorders, including anxiety and depression [1-3]. In the presence of an environmental stressor, the body responds with major modifications of the normal homeostasis, including alterations of the hypothalamicpituitary-adrenal (HPA) axis, the major neuroendocrine system activated by stressful experiences $[4,5]$. Activation of the HPA induced by stress culminates with the release of corticosterone (CORT) from the adrenal glands. These processes are finely controlled by neuronal activity of the hippocampus (HPC) and prefrontal cortex (PFC), which exert a negative feedback on the HPA axis activation. Interestingly, it has been reported that both hyper- and hypoactivation of the HPA axis are associated with increased susceptibility to developing psychiatric disorders $[6,7]$.
In order to better understand the etiology of depression and anxiety and to develop new treatments, valid and reliable animal models are needed [8]. Several chronic stress methods, either physical or psychosocial, have been described to promote modifications in behavior, brain structure, and neuroendocrine system in rodents [8-12]. Because psychiatric disorders in humans have been linked prevalently with social stress and/or reduced social interaction rather than physical stress [13-16], there is an increasing interest in developing chronic social stress paradigms for modeling psychiatric disorders in animal models. Different models of chronic social stress are able to induce various modifications in the behavior, brain function, and neuroendocrine system [17-20]. While it has been extensively reported that social isolation (SI) rearing induces long-lasting effects on behavior and brain structure in rodents, the behavioral consequences of SI in adult animals, especially in mice, have been less 
investigated [21-27]. Moreover, the molecular mechanisms underlying these modifications are still not fully understood.

Chronic stress-induced behavioral modifications have been correlated with changes of neuroplasticity-related genes in different brain areas, including neurotrophic factors, metabotropic glutamate receptors, and immediate early genes [11, 28-31]. In particular, Brain-Derived Neurotrophic Factor (BDNF), a brain plasticity marker, has been extensively investigated and associated with stress response, depression, and anxiety [31-36]. The BDNF gene is a complex gene, formed by at least eight $5^{\prime}$ noncoding exons, each of which can be alternatively spliced to a common $3^{\prime}$ protein-coding exon, to generate different transcripts $[37,38]$. The complex structure of the BDNF gene allows the distinct BDNF splice variants to be differentially expressed in subcellular localizations, in specific brain regions and in response to distinct stimuli $[35,36,38-41]$. However, it is not known whether and how the BDNF splice variants are differentially regulated in the HPC and PFC of socially isolated mice.

In this study, we assessed the effect of SI stress on anxious- and depressive-like behaviors in adult male mice. Moreover, we measured the plasma CORT levels and the adrenal gland weight in socially isolated and grouped mice. Finally, we investigated whether the expression of total BDNF, BDNF splice variants, and other neuroplasticity-related genes (mGluR1, mGluR2, mGluR5, c-Fos, Arc, and Egr-1) were altered in the HPC and PFC of socially isolated compared to grouped adult male mice.

\section{Materials and Methods}

2.1. Animals. Male C57BL/6J mice that are 8 weeks old were purchased from Charles River (Calco, Italy) and allowed to acclimatize 1 week before being randomly divided in socially isolated (SI) and group-housed $(\mathrm{GH})$ groups. Mice were maintained in a standard $12 \mathrm{~h}$ light/dark cycle, temperature controlled room $\left(21 \pm 1^{\circ} \mathrm{C}\right)$, with access to food and water ad libitum.

All animal procedures were conducted according to current regulations for animal experimentation in Italy and the European Union and were approved by the Italian Ministry of Health. To reduce the number of animals used, in agreement with the $3 \mathrm{R}$ guidelines, we performed behavioral and molecular analysis in the same cohort of mice. All experimental procedures involving animals were performed in accordance with the European Community Council Directive $86 / 609 /$ EEC and were approved by Italian legislation on animal experimentation (Decreto Legislativo 116/1992).

2.2. Experimental Procedure. Nine-week-old male mice were individually housed (socially isolated: SI) or group-housed (4 mice per cage; group-housed: $\mathrm{GH}$ ) in standard mouse cages. Mice were tested in the open field test (OFT) on day 28 and in the tail suspension test (TST) on day 31 (Figure 1(a)). Mice were sacrificed on day 33 and blood, adrenal glands, HPC, and PFC were harvested (Figure 1(a)).

2.3. Open Field Test. OFT was conducted on day 28 as described in Ieraci and Herrera [42] with some modifications.
Briefly, mice were placed in the center of a $40 \times 40 \mathrm{~cm}$ square arena divided into central $(20 \mathrm{~cm} \times 20 \mathrm{~cm})$ and peripheral areas, with $35 \mathrm{~cm}$ high walls, for $10 \mathrm{~min}$. The test was conducted in a dimly lit room. The total distance traveled and the time spent in the central and peripheral areas were analyzed by a video-tracking system (Any-Maze purchased by Ugo Basile, Varese, Italy).

2.4. Tail Suspension Test. TST was performed on day 31 as described by Steru et al. [43]. Briefly, mice were individually suspended by an adhesive tape, placed about $1 \mathrm{~cm}$ from the tip of the tail, on a horizontal bar $50 \mathrm{~cm}$ above from the bench top within a visually isolated area. A 6 min test session was videotaped and an experimenter, blinded to the experimental groups, recorded the total immobility time (defined as passive hanging without any movements except respiration).

2.5. Adrenal Weight. To assess whether chronic social isolation stress affects adrenal glands weight, SI and GH mice were sacrificed on day 33 and adrenal glands were removed and pruned from fat and weighed. The left and right adrenals were weighted separately for each animal. Values are reported as the adrenal/total body weight ratio $(\mathrm{mg} / \mathrm{g})$.

2.6. Corticosterone Assay. For CORT levels measure, trunk blood was collected on ice-cooled microcentrifuge tube

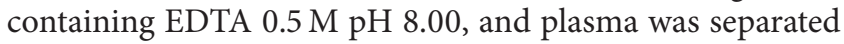
by centrifugation and stored at $-80^{\circ} \mathrm{C}$. CORT levels were measured using the corticosterone ELISA Kit (Enzo Life Sciences, Florence, Italy) according to the manufacturer's instructions.

2.7. RNA Isolation and Reverse Transcription. Total RNA from HPC and PFC was extracted using the Direct-zol RNA MiniPrep (Zymo Research, purchased by Euroclone, Milan, Italy) according to manufacturer's instructions and then quantified by absorption at $A_{260 \mathrm{~nm}}$ measured by UV spectrophotometry (NanoVue, GE Healthcare Europe GmbH, Milan, Italy). cDNA was synthesized from $1 \mu \mathrm{g}$ of DNasetreated total RNA using the iScript kit (Biorad, Milan, Italy) according to manufacturer's instructions.

2.8. Quantitative Real-Time PCR. qPCR analysis of mRNA expression levels was performed on a 7900HT Fast PCR System (Applied Biosystems, Monza, Italy) and iTaq Universal SYBR Green supermix (Biorad), as previously described [35]. Primers used are listed in Table 1 and were either de novo designed or previously published elsewhere $[35,44]$. PCR cycling conditions were $10 \mathrm{~min}$ at $95^{\circ} \mathrm{C}, 40$ cycles of $15 \mathrm{~s}$ at $95^{\circ} \mathrm{C}$, and $1 \mathrm{~min}$ at $60^{\circ} \mathrm{C}$. Relative expression of mRNA for the target genes was performed by the comparative $\mathrm{C}_{\mathrm{T}}\left(\Delta \Delta \mathrm{C}_{\mathrm{T}}\right)$ method using $\beta$-actin and $\mathrm{GAPDH}$ as control reference genes. The relative mRNA levels were expressed as fold change. Analysis of melting curve verified the specificity of the PCR products.

2.9. Western Blot. Western blot was performed as previously described [45]; briefly HPC and PFC were lysed in icecold RIPA buffer $(0.15 \mathrm{mM} \mathrm{NaCl}, 0.05 \mathrm{mM}$ Tris_HCl, $\mathrm{pH}$ 


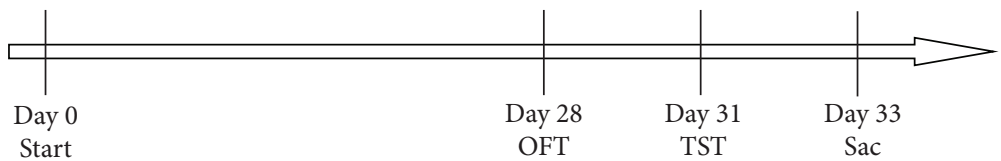

(a)

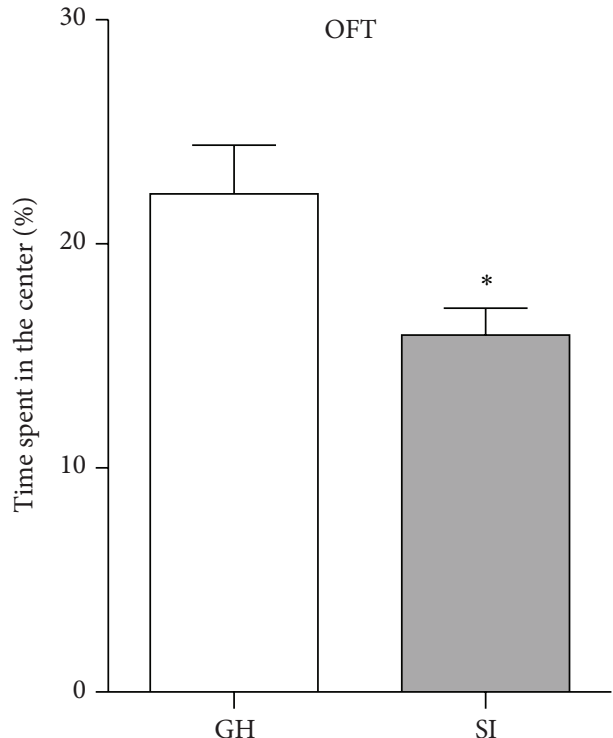

(b)

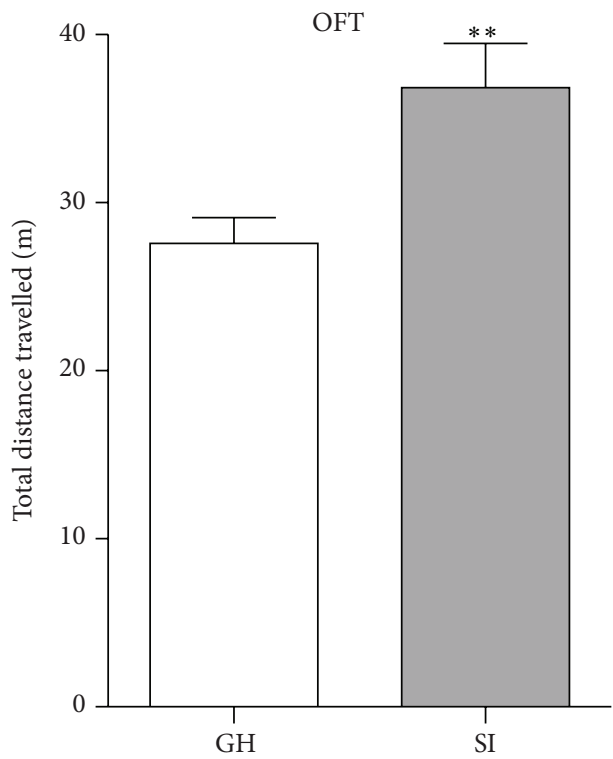

(d)

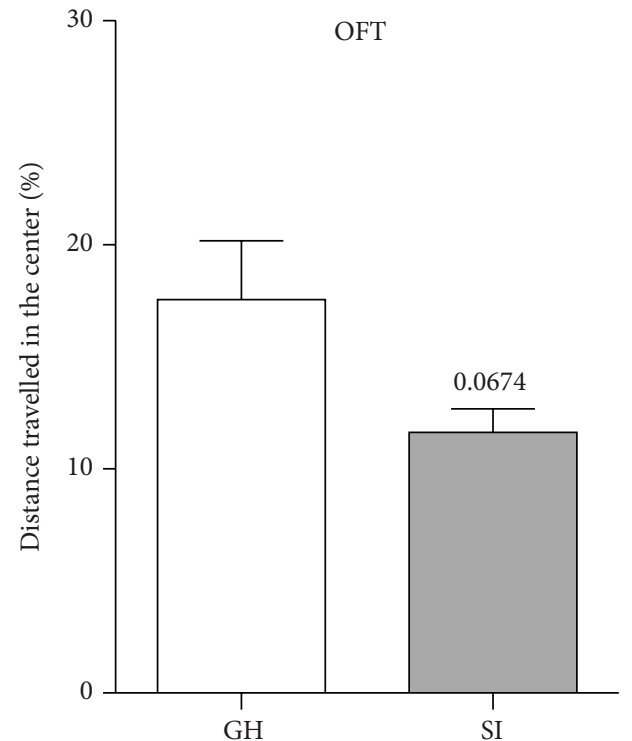

(c)

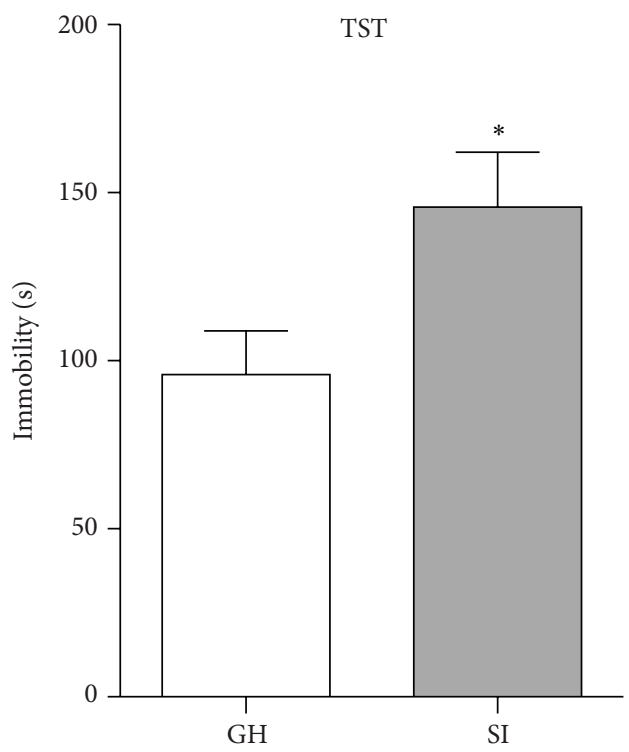

(e)

Figure 1: (a) Experimental schedule. Nine-week-old male mice were housed in groups (GH) or socially isolated (SI) throughout the experimental period. The open field test (OFT) and the tail suspension test (TST) were conducted on days 28 and 31, respectively. Animals were sacrificed on day 33. (b-e) Chronic adult social isolation stress induced hyperactivity and anxiety- and depressive-like behaviors in male mice. In the OFT, SI mice showed reduced percentage of time spent in the center (b), increased total distance travelled (d), and only a tendency to decreased percentage of distance travelled in the center (c). In the TST, SI mice showed increased total immobility time (e). Data are presented as mean $\pm \operatorname{SEM}(n=7-8$ per group $) .{ }^{*} p<0.05 ;{ }^{* *} p<0.01$. 
TABLE 1: List and sequence of primers used in this study.

\begin{tabular}{|c|c|c|}
\hline Gene & Forward & Reverse \\
\hline \multicolumn{3}{|c|}{ Real-time PCR } \\
\hline BDNF- $1^{\mathrm{a}}$ & CCTGCATCTGTTGGGGAGAC & CGCCTTCATGCAACCGAAGTAT \\
\hline BDNF- $2^{\mathrm{a}}$ & АССТTTTССТССТССТGCG & TGGATGAAGTACTACCACCTCGG \\
\hline BDNF- $3^{\mathrm{a}}$ & TGAGACTGCGCTCCACTCCC & CGCCTTCATGCAACCGAAGTAT \\
\hline BDNF- $4^{\mathrm{a}}$ & CAGAGCAGCTGCCTTGATGTTT & CGCCTTCATGCAACCGAAGTAT \\
\hline BDNF- $6^{\mathrm{a}}$ & ACAATGTGACTCCACTGCCGG & CGCCTTCATGCAACCGAAGTAT \\
\hline BDNF-7 ${ }^{\mathrm{a}}$ & ACTTACAGGTCCAAGGTCAACG & GGACAGAGGGTCGGATACAG \\
\hline $\mathrm{BDNF}-8^{\mathrm{a}}$ & ATGACTGTGCATCCCAGGAGAAA & CGCCTTCATGCAACCGAAGTAT \\
\hline $\mathrm{BDNF}^{\mathrm{a}}$ & TCGTTCCTTTCGAGTTAGCC & TTGGTAAACGGCACAAAAC \\
\hline mGluR1 & CACAGCCCTTGCCAAAGAGAATGAG & CACTCCACTCGAGGTTAACGGA \\
\hline mGluR2 & CACCACCTGTATCATCTGGCTG & GAGCACCACAGAGCCACTGA \\
\hline mGluR5 & AGACGACCTGGCCAAACAAA & CTACTGCTCATGAAAGCCCACA \\
\hline c-Fos ${ }^{b}$ & CTGCAGCCAAGTGCCGGAATC & GGCAATCTCAGTCTGCAACGC \\
\hline Arc & AGCCCAAACTCAAGCGCTTT & GAAGGCTCAGCTGCCTGCCTC \\
\hline Egr-1 $1^{b}$ & ССТTCAATCCTCAAGGGGAGC & AACCGAGTCGTTTGGCTGGGA \\
\hline$\beta$-Actin ${ }^{\mathrm{a}}$ & GCCAGAGCAGTAATCTCCTTCT & AGTGTGACGTTGACATCCGTA \\
\hline $\mathrm{GAPDH}^{\mathrm{a}}$ & CGTGCCGCCTGGAGAAACC & TGGAAGAGTGGGAGTTGCTGTTG \\
\hline
\end{tabular}

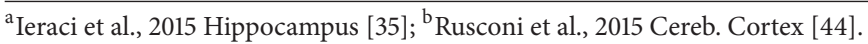

7.2, $1 \%$ Triton X-100, $1 \%$ sodium deoxycholate, and $0.1 \%$ SDS) with Protease Inhibitor Cocktail (Sigma-Aldrich, Milan, Italy). Protein concentration was determined by the Quantum Bicinchoninic Protein Assay (Euroclone) and $15 \mu \mathrm{g}$ of proteins was separated on SDS-PAGE gels and transferred to a polyvinylidene difluoride membrane (GE Healthcare, Amersham, Milan, Italy), followed by blocking in 5\% milk dissolved in Tris Buffer Saline-Tween 20 (TBST). Membranes were incubated with anti-BDNF $(1: 2,000$, rabbit polyclonal, Alomone, Jerusalem, Israel) or anti- $\beta$-actin $(1: 20,000$, mouse monoclonal, Sigma) antibodies. After washing with TBST, filters were incubated with peroxidase-conjugated secondary anti-rabbit $(1: 3,000$, Sigma-Aldrich) or with the fluorescent IRDye secondary anti-mouse antibody (LI-COR, purchased from Carlo Erba Reagents, Milan, Italy). Peroxidase immunoreactivity bands were revealed by chemiluminescence using ECL detection system (Biorad). Chemiluminescence and fluorescence membrane signals were scanned and quantified in an Odyssey LI-COR scanner (Carlo Erba Reagents).

2.10. Statistical Analysis. Statistical analyses were performed using GraphPad Prism 6 (GraphPad Software, La Jolla, CA). Data are presented as mean \pm standard error of the mean (SEM). Statistical analyses were made using unpaired $t$-test or two-way analysis of variance (ANOVA), and LSD procedure was used for multiple comparison analysis. Pearson's $r$ correlations were performed to assess the correlation between CORT levels, gene expression levels, and behavioral analyses (Tables 2-7).

\section{Results}

3.1. Social Isolation Stress Induces Behavioral Impairments in Adult Male Mice. To assess whether social isolation induces
TABLE 2: Pearson's correlation between corticosterone levels and behavioral analysis.

\begin{tabular}{lcc}
\hline & \multicolumn{2}{c}{ HPC } \\
\hline \% time spent in the center & 0.1178 & $p$ \\
\% distance in the center & -0.07975 & 0.6759 \\
Total distance travelled & -0.4050 & 0.7776 \\
Tail suspension test & $-\mathbf{0 . 6 3 6 7}$ & 0.1343 \\
\hline
\end{tabular}

modifications of emotional behavior in adult mice, 9-weekold male mice were randomly housed in group $(\mathrm{GH})$ or socially isolated (SI) for 4 weeks and then tested in the OFT and in the TST to measure the anxious- and depressivelike behaviors, respectively (Figure 1(a)). SI mice spent significantly less time in the center of the arena $(p=0.029)$ (Figure 1(b)) and showed a tendency to a reduced distance travelled in the center $(p=0.067$ ) (Figure 1(c)), indicating anxious-like behavior. Interestingly, SI mice showed an increased level of total distance travelled in the OFT as compared to the $\mathrm{GH}$ mice $(p=0.007)$ suggesting a hyperactivity phenotype in SI mice (Figure 1(d)). Moreover, in the TST, the SI exhibited a significantly higher period of immobility time compared to the GH mice ( $p=0.03)$, indicating a depressive-like behavior in SI mice (Figure 1(e)).

3.2. Corticosterone Plasma Levels Are Decreased in Socially Isolated Adult Male Mice. To study whether the behavioral changes induced by social isolation are associated with alterations of the HPA axis function, we measured the plasma CORT levels and the adrenal glands weight, as an index of terminal phase of the HPA activation, in the SI and GH mice. Interestingly, the levels of plasma CORT were markedly 
TABLE 3: Pearson's correlation between corticosterone and gene expression levels.

\begin{tabular}{lcccc}
\hline & \multicolumn{2}{c}{ HPC } & \multicolumn{2}{c}{ PFC } \\
& $r$ & $p$ & $r$ & $p$ \\
\hline Total BDNF & 0.1281 & 0.6490 & -0.1253 & 0.6438 \\
BDNF-1 & 0.01566 & 0.9558 & -0.04050 & 0.8816 \\
BDNF-2 & 0.003361 & 0.9905 & 0.2474 & 0.3556 \\
BDNF-3 & -0.4312 & 0.1085 & 0.2589 & 0.3330 \\
BDNF-4 & -0.06950 & 0.8056 & -0.1629 & 0.5467 \\
BDNF-6 & 0.1259 & 0.6549 & 0.1538 & 0.5695 \\
BDNF-7 & $\mathbf{0 . 5 5 5 2}$ & $\mathbf{0 . 0 3 1 7}$ & $\mathbf{0 . 4 9 3 3}$ & $\mathbf{0 . 0 5 2 2}$ \\
BDNF-8 & -0.09168 & 0.7452 & 0.2692 & 0.3133 \\
mGluR1 & 0.07396 & 0.7934 & 0.3207 & 0.2439 \\
mGluR2 & 0.01753 & 0.9506 & 0.3320 & 0.2267 \\
mGluR5 & 0.2400 & 0.3890 & -0.4608 & 0.0839 \\
c-Fos & 0.3787 & 0.1639 & 0.4177 & 0.1214 \\
Arc & 0.4144 & 0.1246 & 0.3985 & 0.1412 \\
Egr-1 & 0.3721 & 0.1720 & 0.4619 & 0.0830 \\
\hline
\end{tabular}

TABLE 4: Pearson's correlation between the percentage time spent in the open field center and gene expression levels.

\begin{tabular}{lcccc}
\hline & \multicolumn{2}{c}{ HPC } & \multicolumn{2}{c}{ PFC } \\
& $r$ & $p$ & $r$ & $p$ \\
\hline Total BDNF & $\mathbf{0 . 5 4 5 9}$ & $\mathbf{0 . 0 3 5 3}$ & -0.01596 & 0.9550 \\
BDNF-1 & -0.06687 & 0.8128 & -0.3120 & 0.2576 \\
BDNF-2 & 0.3161 & 0.2510 & 0.5469 & 0.0349 \\
BDNF-3 & -0.1448 & 0.6066 & 0.08998 & 0.7498 \\
BDNF-4 & 0.07657 & 0.7862 & -0.1619 & 0.5643 \\
BDNF-6 & 0.4217 & 0.1175 & 0.1034 & 0.7138 \\
BDNF-7 & 0.3897 & 0.1510 & $\mathbf{0 . 5 8 8 6}$ & $\mathbf{0 . 0 2 1 0}$ \\
BDNF-8 & -0.4328 & 0.1071 & -0.02065 & 0.9418 \\
mGluR1 & 0.08381 & 0.7665 & $\mathbf{0 . 6 6 8 9}$ & $\mathbf{0 . 0 0 6 4}$ \\
mGluR2 & 0.3911 & 0.1495 & 0.4856 & 0.0665 \\
mGluR5 & 0.2127 & 0.4465 & 0.3362 & 0.2205 \\
c-Fos & $\mathbf{0 . 6 6 2 7}$ & $\mathbf{0 . 0 0 7 1}$ & $\mathbf{0 . 5 7 9 7}$ & $\mathbf{0 . 0 2 3 5}$ \\
Arc & $\mathbf{0 . 5 3 6 0}$ & $\mathbf{0 . 0 3 9 5}$ & $\mathbf{0 . 5 8 2 6}$ & $\mathbf{0 . 0 2 2 7}$ \\
Egr-1 & 0.3196 & 0.2456 & 0.5121 & 0.0510 \\
\hline
\end{tabular}

reduced in the SI mice compared to GH mice $(p=0.002)$ (Figure 2(a)). Moreover, a negative Pearson's correlation was specifically detected between the immobility time measured in the TST and the plasma CORT levels $(r=-0.6367 ; p=$ 0.0107; Table 2). A two-way ANOVA showed a significant overall effect for the size of the adrenal glands $\left(F_{(1,26)}=5.704\right.$; $p=0.0245)$, with the left adrenal gland heavier than the right one (Figure 2(b)), consistent with the data reported in literature $[46,47]$. A further Fisher's LSD post hoc analysis revealed a significant difference between the right and left adrenal gland for the GH mice $(p=0.03)$, but not for the SI mice $(p=0.19)$ (Figure 2(b)). These differences were not due to changes in body weight $(p=0.45)$ (Figure 2(c)).

3.3. Neuroplasticity-Related Genes Are Reduced in the HPC and PFC of Socially Isolated Adult Male Mice. To investigate
TABLE 5: Pearson's correlation between the percentage distance travelled in the open field center and gene expression levels.

\begin{tabular}{lcccc}
\hline & \multicolumn{2}{c}{ HPC } & \multicolumn{2}{c}{ PFC } \\
& $r$ & $p$ & $r$ & $p$ \\
\hline Total BDNF & 0.2967 & 0.2829 & -0.2008 & 0.4731 \\
BDNF-1 & -0.1696 & 0.5456 & -0.4613 & 0.0835 \\
BDNF-2 & 0.005426 & 0.9847 & 0.1432 & 0.6106 \\
BDNF-3 & -0.05189 & 0.8543 & 0.09637 & 0.7326 \\
BDNF-4 & 0.02956 & 0.9167 & -0.3317 & 0.2271 \\
BDNF-6 & 0.2578 & 0.3536 & -0.08952 & 0.7510 \\
BDNF-7 & 0.1517 & 0.5895 & 0.3941 & 0.1461 \\
BDNF-8 & -0.2511 & 0.3668 & 0.01725 & 0.9514 \\
mGluR1 & 0.1989 & 0.4772 & $\mathbf{0 . 5 1 7 9}$ & $\mathbf{0 . 0 4 8 0}$ \\
mGluR2 & 0.3364 & 0.2202 & 0.4008 & 0.1388 \\
mGluR5 & 0.2203 & 0.4302 & 0.4895 & 0.0640 \\
c-Fos & 0.3250 & 0.2373 & 0.3312 & 0.2278 \\
Arc & 0.2202 & 0.4303 & 0.2744 & 0.3222 \\
Egr-1 & 0.1294 & 0.6458 & 0.2010 & 0.4727 \\
\hline
\end{tabular}

TABLE 6: Pearson's correlation between the total distance travelled in the open field and gene expression levels.

\begin{tabular}{lcccc}
\hline & \multicolumn{2}{c}{ HPC } & \multicolumn{2}{c}{ PFC } \\
& $r$ & $p$ & $r$ & $p$ \\
\hline Total BDNF & -0.01723 & 0.9514 & 0.2982 & 0.2804 \\
BDNF-1 & 0.4873 & 0.0654 & 0.3025 & 0.2731 \\
BDNF-2 & -0.06728 & 0.8117 & 0.1369 & 0.6266 \\
BDNF-3 & 0.5139 & 0.0500 & 0.3978 & 0.1420 \\
BDNF-4 & 0.3485 & 0.2030 & 0.1766 & 0.5289 \\
BDNF-6 & 0.1649 & 0.5571 & 0.2295 & 0.4107 \\
BDNF-7 & -0.3760 & 0.1672 & $-\mathbf{0 . 5 1 0 7}$ & $\mathbf{0 . 0 5 1 7}$ \\
BDNF-8 & 0.1553 & 0.5806 & 0.09135 & 0.7461 \\
mGluR1 & -0.1733 & 0.5367 & -0.4017 & 0.1378 \\
mGluR2 & 0.1448 & 0.6066 & -0.3355 & 0.2215 \\
mGluR5 & 0.03919 & 0.8897 & -0.02266 & 0.9361 \\
c-Fos & -0.4212 & 0.1180 & -0.3366 & 0.2200 \\
Arc & -0.3860 & 0.1553 & -0.2858 & 0.3017 \\
Egr-1 & -0.1496 & 0.5947 & -0.4556 & 0.0879 \\
\hline
\end{tabular}

the possible molecular mechanisms underlying the social isolation stress-induced behavioral changes, we evaluated the mRNA levels of different genes involved in neuronal plasticity in the HPC and PFC of SI and GH mice. Firstly, we measured the mRNA levels of total BDNF, which is known to modulate stress-induced behavioral changes [34], and BDNF splice variants $1,2,3,4,6,7$, and 8 . We found that BDNF-7 transcript was significantly and selectively downregulated in both the HPC and the PFC of SI mice, compared to GH mice (HPC: $p=0.028$; PFC: $p=0.01$ ) (Figure 3 ), while no significant differences were revealed for total BDNF and all the other BDNF transcripts analyzed (Figure 3). Protein levels analysis by Western blot revealed only a trend for reduction of proBDNF in the HPC $(p=0.082$; Figure $3(\mathrm{c}))$ and mature BDNF in the PFC $(p=0.085$; Figure $3(\mathrm{~d}))$. 


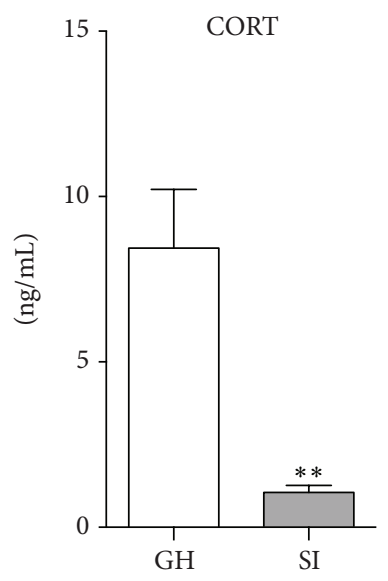

(a)

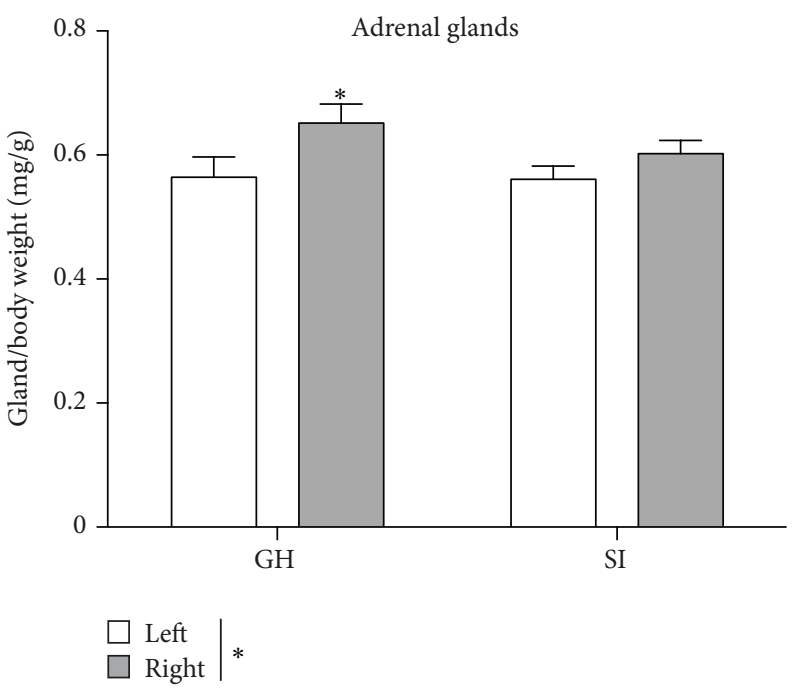

(b)

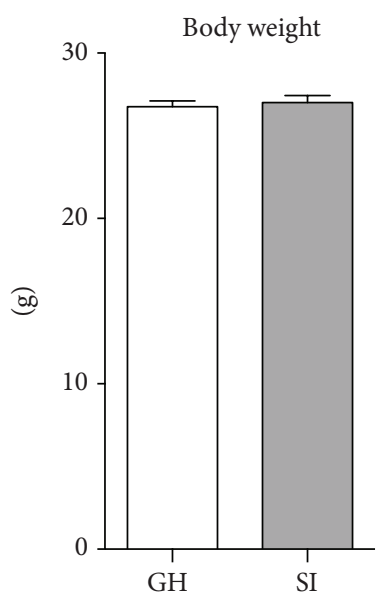

(c)

FIGURE 2: Chronic social isolation stress in adulthood reduces plasma corticosterone levels. (a) Corticosterone levels were reduced in the plasma of socially isolated adult male mice. (b) Socially isolated mice showed reduced differences between the left and right adrenal/body weight ratio. (c) There were no differences in the total body weight between group-housed (GH) and socially isolated (SI) mice. Data are presented mean $\pm \operatorname{SEM}(n=7-8$ per group $) .{ }^{*} p<0.05 ;{ }^{* *} p<0.01$

TABle 7: Pearson's correlation between the immobility time measured in the tail suspension test and gene expression levels.

\begin{tabular}{lcccc}
\hline & \multicolumn{2}{c}{ HPC } & \multicolumn{2}{c}{ PFC } \\
& $r$ & $p$ & $r$ & $p$ \\
\hline Total BDNF & -0.2868 & 0.3000 & -0.3003 & 0.2768 \\
BDNF-1 & 0.1625 & 0.5628 & -0.2971 & 0.2822 \\
BDNF-2 & 0.1307 & 0.6425 & -0.1610 & 0.5665 \\
BDNF-3 & $\mathbf{0 . 6 5 8 0}$ & $\mathbf{0 . 0 0 7 7}$ & -0.3290 & 0.2311 \\
BDNF-4 & 0.2176 & 0.4359 & -0.2689 & 0.3325 \\
BDNF-6 & -0.1178 & 0.6759 & -0.3714 & 0.1729 \\
BDNF-7 & -0.1460 & 0.6036 & -0.3611 & 0.1860 \\
BDNF-8 & 0.1389 & 0.6215 & 0.1938 & 0.4888 \\
mGluR1 & 0.1182 & 0.6748 & -0.1393 & 0.6205 \\
mGluR2 & 0.00844 & 0.9762 & -0.05227 & 0.8532 \\
mGluR5 & 0.1913 & 0.4947 & 0.2808 & 0.3107 \\
c-Fos & -0.2720 & 0.3267 & -0.2640 & 0.3417 \\
Arc & -0.3338 & 0.2241 & -0.2845 & 0.3040 \\
Egr-1 & -0.09785 & 0.7286 & -0.1392 & 0.6208 \\
\hline
\end{tabular}

Interestingly, we have observed a significant positive correlation between the plasma CORT levels and the BDNF-7 mRNA levels measured in the HPC, with only a trend in the PFC (HPC: $r=0.5552$; $p=0.0317$; PFC: $r=0.4933$; $p=$ 0.0522; Table 3). Total BDNF mRNA levels in the HPC and BDNF-7 mRNA levels in the PFC positively correlate with the percentage of time spent in the OF center (total BDNF: $r=0.5459 ; p=0.0353$; BDNF-7: $r=0.5886 ; p=0.021$; Table 4). Moreover, we found a trend for correlation between the cortical BDNF-7 levels and the total distance travelled in the OF ( $r=-0.5107 ; p=0.0517$; Table 6).
Several lines of evidence suggest that metabotropic glutamate receptors are involved in stress-related disorders and in the mechanisms of action of antidepressants [48-50]. Thus, we sought to investigate whether behavioral modifications induced by SI stress correlated with changes in the expression of mGluR1, mGluR2, and mGluR5 in the HPC and PFC. Interestingly, we found that mGluR1 and mGluR2 mRNA levels were significantly reduced in the PFC of SI mice compared to GH mice (mGluR1: $p=0.012$; mGluR2: $p=$ 0.038; Figure 4(b)), while no differences were revealed for mGluR5 mRNA levels in the PFC and for all three mRNA levels in the HPC between SI and GH mice (Figures 4(a)4(b)). However, only mGluR1 in the PFC showed a positive correlation with the percentage of time spent in the OF center $(r=0.5886 ; p=0.021$; Table 4$)$ and the distance travelled in the OF center ( $r=0.5886 ; p=0.021$; Table 5$)$.

Immediate early genes (IEGs) are genes rapidly expressed upon different stimuli and play important roles in synaptic plasticity [51]. However, constitutive changes in IEGs expression have been reported also after chronic stress and antidepressant treatments [52-54]. Therefore, to investigate whether SI induced alterations in the IEGs expression, we evaluated the mRNA levels of c-Fos, Arc, and Egr-1 in the $\mathrm{HPC}$ and PFC of SI and GH mice. We found that mRNA levels of c-Fos, Arc, and Egr-1 were decreased in both HPC and PFC of SI mice compared to GH mice (HPC: c-Fos: $p=0.0092$; Arc: $p=0.016$; Egr-1: $p=0.027$; PFC: $\mathrm{c}-\mathrm{Fos}: p=0.0099$; Arc: $p=0.029$; Egr-1: $p=0.69$ ) (Figures 4(c)-4(d)). A significant positive correlation was found for c-Fos and Arc mRNA levels in the HPC and PFC and the percentage of time spent in the OF center (HPC: c-Fos: $r=0.6627 ; p=0.0071$; Arc: $r=0.536 ; p=0.0395$; PFC: c-Fos: $r=0.5797 ; p=0.035$; Arc: $r=0.5826 ; p=0.0227$; Table 4). 


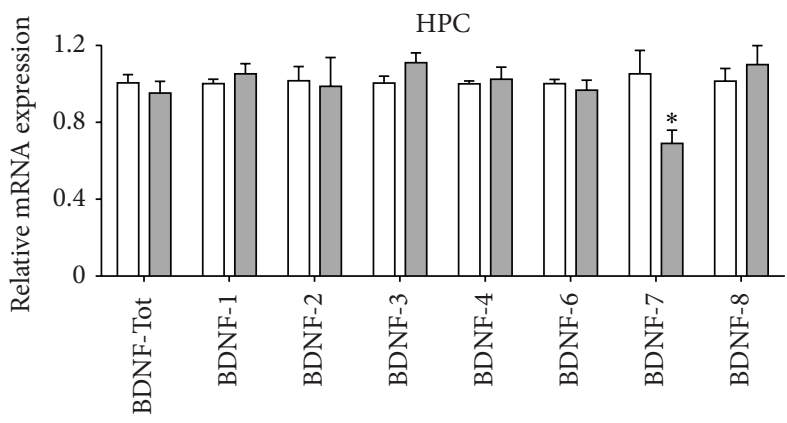

$\square \mathrm{GH}$

$\square$ SI

(a)

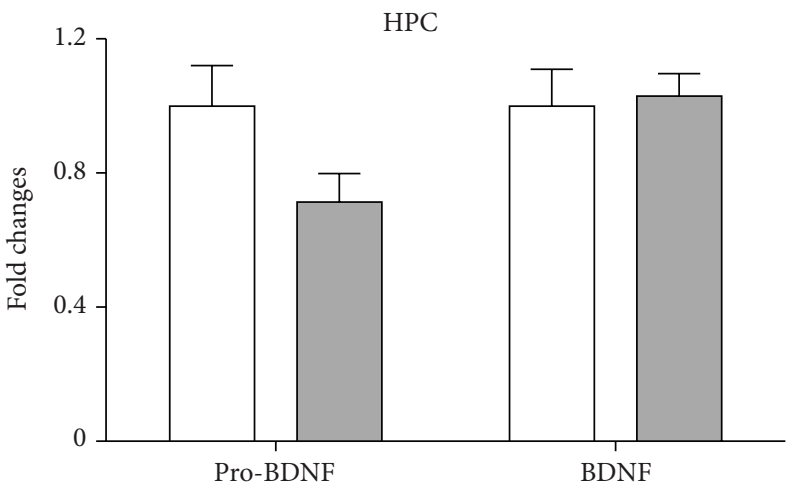

$\square \mathrm{GH}$

$\square$ SI

(c)

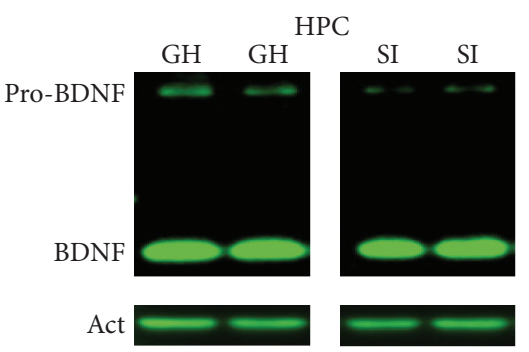

(e)

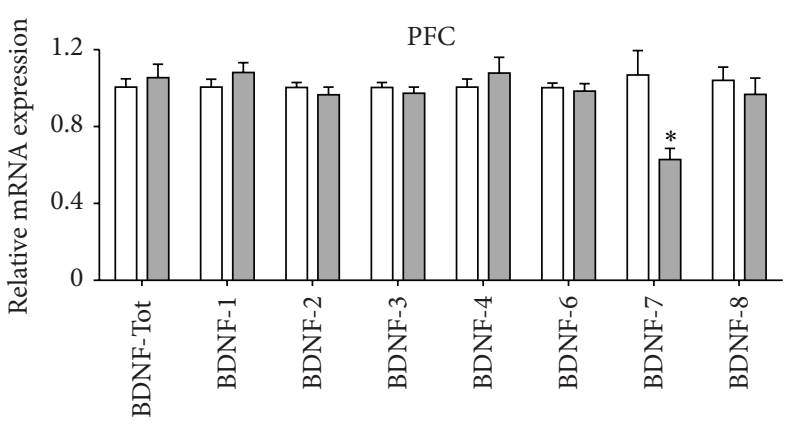

$\square \mathrm{GH}$

$\square$ SI

(b)

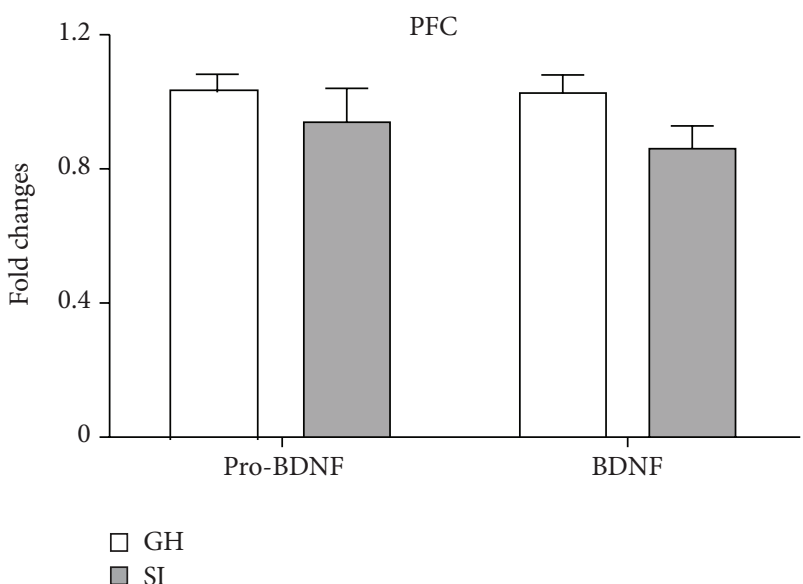

(d)

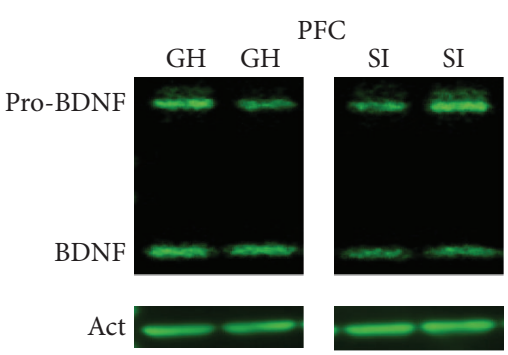

(f)

FIGURE 3: Social isolation stress in adulthood reduces BDNF-7 splice variants in the hippocampus (HPC) and prefrontal cortex (PFC). (a-b) Adult socially isolated mice showed decreased levels of BDNF-7 mRNA transcript in the HPC (a) and PFC (b). On the contrary, total BDNF and BDNF splice variants $1,2,3,4,6$, and 8 were not modulated by adult SI stress. Data are presented as Mean \pm SEM ( $n=7-8$ per group). ${ }^{*} p<0.05$. (c-f) Pro-BDNF and mature BDNF protein levels in the HPC (c, e) and prefrontal cortex (d, f). Densitometric quantifications were obtained as ratio of Pro-BDNF/ $\beta$-actin and BDNF/ $\beta$-actin. Data are presented as mean \pm SEM ( $n=6$ per group). (e-f) Representative Western blot pictures from Pro-BDNF, BDNF, and $\beta$-actin.

\section{Discussion}

In the present study, we have found that SI adult male mice spend less time in the center and are hyperactive in the OFT. Additionally, SI mice showed higher immobility time in the tail suspension test compared to GH mice. Although several studies have reported that SI rearing induces hyperactivity and anxious- and depressive-like behavior in rodents, only a few studies have addressed the consequences of SI in adult rodents, especially in mice [21, 23, 55-59]. Our findings suggest that social deprivation may be deleterious not only during childhood and adolescent period but also during adulthood in male mice. Moreover, our results are consistent with previous data showing that stress induces hyperactivity in rodents in response to exposure to novel environments, such as an open field [52, 60-63].

The reduced plasma CORT levels measured in SI adult mice are paralleled by the decreased difference in weight between the left and right adrenal glands, suggesting that this hypofunction may be due to morphological changes in the 


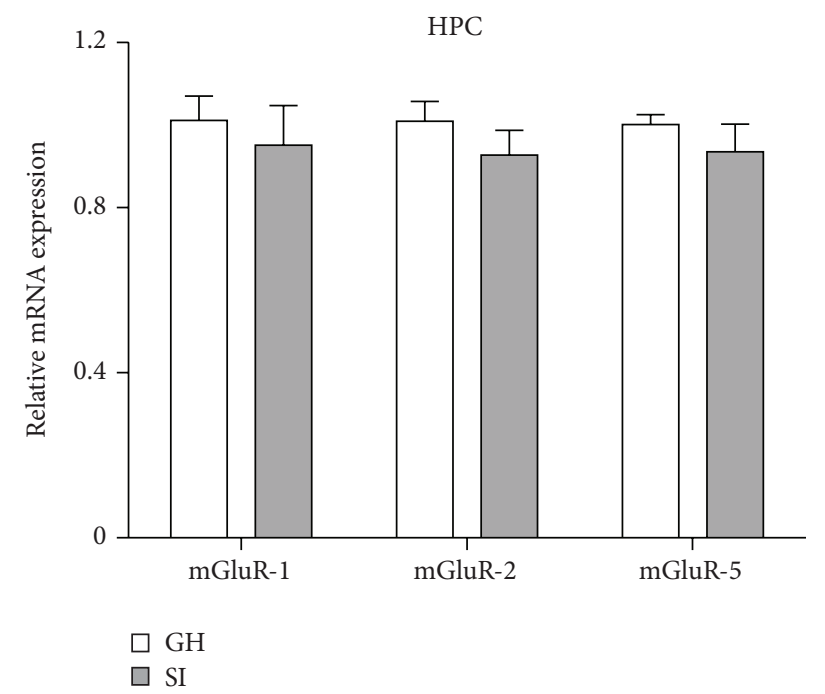

(a)

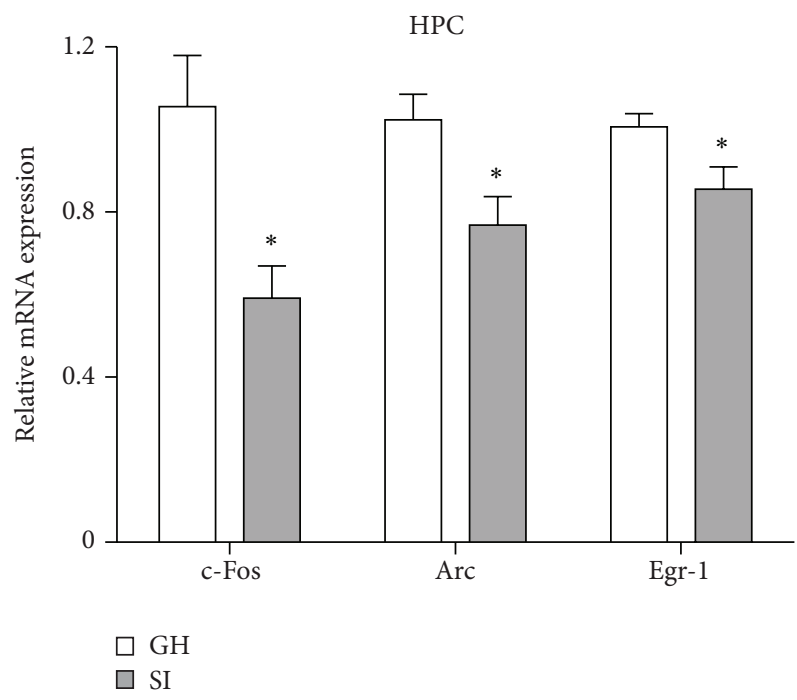

(c)

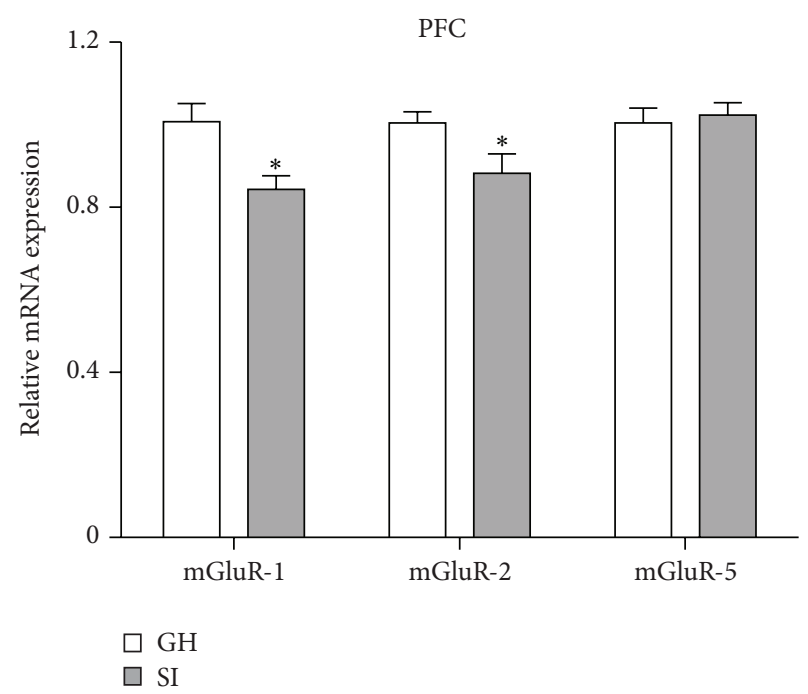

(b)

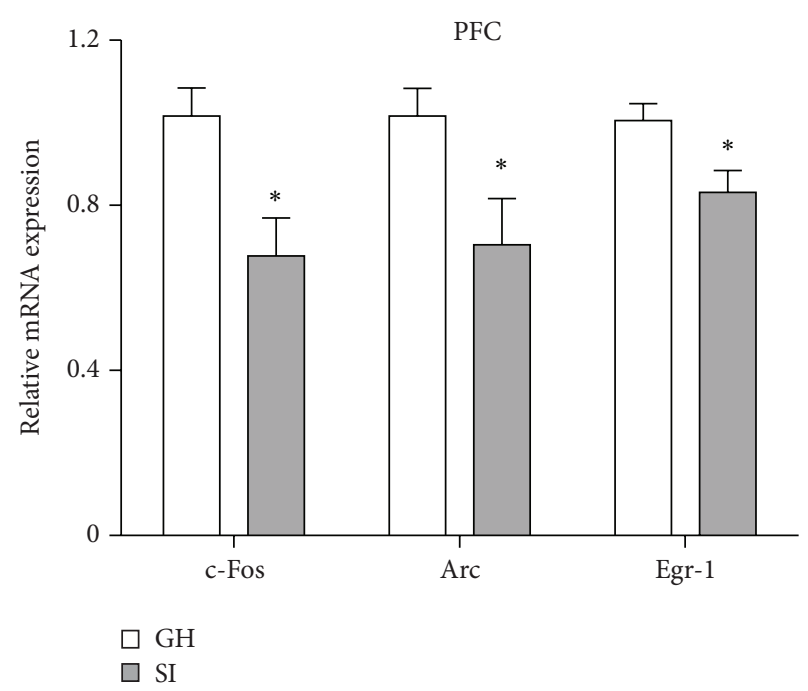

(d)

FIGURE 4: Social isolation stress in adulthood decreases expression of neuroplasticity-related gene in the hippocampus (HPC) and prefrontal cortex (PFC). (a, b) In socially isolated (SI) adult male mice, mGluR1 and mGluR2 mRNA levels were reduced in the PFC (b). No differences were revealed for mGluR5 in the PFC and for mGluR1, mGluR2, and mGluR5 in the HPC (a-b). SI mice showed reduced mRNA levels of c-Fos, Arc, and Egr-1 in the HPC and PFC (c-d). Data are presented as mean \pm SEM $\left(n=7-8\right.$ per group). ${ }^{*} p<0.05$.

HPA axis. Although stress is usually correlated with HPA hyperactivity, our results are in line with previous reports showing reduced levels of CORT in SI adult male rat and female mice $[55,56]$. Moreover, lower adrenal activity in response to chronic stress was also reported in social defeat animal models [64]. Interestingly, reduced basal levels of CORT have been reported in patients with posttraumatic stress disorder (PTSD), even decades after the traumatic events [65-67]. Clinical studies have also reported lower CORT levels in some patients at risk for PTSD and in healthy subjects living under constantly stressful environments [68, 69]. Intriguingly, it has been reported that rats with reduced basal levels of CORT display increased anxious-like behavior and low extinctions rates of conditioned fear, behavioral disturbances that model some aspect of PTSD [70]. Delayed and incomplete contextual fear extinction has been also described in SI adult mice [23]. Altogether these lines of evidence suggest that social isolation stress in adult mice could be a suitable model to study the behavioral and molecular alterations related to PTSD [23]. However, further studies will be necessary to fully characterize this model.

The results showing that SI stress in adult male mice downregulated the expression of IEGs are consistent with previous reports showing that social isolation rearing reduced IEGs in rats [52, 71, 72]. IEGs are defined by their capability to be quickly transcribed without new protein synthesis, activated by transcription factors that are regulated by phosphorylation. We measured the levels of gene expression 2 
days after the TST to limit the possibility that behavioral tests affected the gene expression. Therefore, the downregulation of IEGs observed here likely reflects an adaptation to the chronic SI stress used, rather than the behavioral manipulation effects. However, we cannot exclude that the downregulation observed is due to the sum of social isolation and behavioral test manipulations.

We found that SI stress decreased Arc expression in both of the HPC and PFC. It has been previously reported that Arc mRNA is delivered to dendrites, where it is specifically accumulated at recently activated synapses and locally translated into protein [73]. Arc has a critical role in neuroplasticity and behavioral processes [74]. Our finding that reduced Arc expression correlated with increased anxietyand depression-like phenotypes in SI adult mice is consistent with previous data showing that Arc expression is higher in the low-anxious Sprague-Dawley rats compared to the highly anxious hooded PVG strain and that chronic antidepressant treatment increased Arc expression [54, 75]. Altogether, these data suggest that Arc may have a direct role in the synaptic plasticity responses after activation and in behavioral processes, coupling neuronal activity with structural remodeling and functional changes [76, 77]. Interestingly, Egr-1 is a transcriptional factor directly controlling the expression of Arc that has also been associated with some form of synaptic plasticity and may be required for the development of late long-term potentiation and behavioral responses [7880]. The present results, showing that both Egr-1 and Arc are decreased in HPC and PFC, may suggest that Arc is downregulated as a consequence of stress-induced reduction of Egr-1 expression.

Remarkably, we found that BDNF-7 transcript was selectively reduced in both HPC and PFC of SI mice, while the levels of total BDNF and all other exons were not changed. As a rule, BDNF-7 mRNA levels are lower compared to the most abundant BDNF transcripts in the brain $(1,2,4$, and 6); therefore the reduction of BDNF-7 levels observed in SI mice is probably not enough to significantly reduce the total expression of BDNF (which includes all transcripts). However, the BDNF-7 transcript is more efficiently translated to protein, compared to more highly expressed BDNF transcripts 1, 4, and 6 [81] and is one of the few BDNF transcripts to be present in the dendrites in basal conditions [82]. It has been reported that synaptic plasticity controls local dendritic BDNF translation and that alterations in this pathway may compromise the long-lasting spine plasticity and lead to behavioral dysfunctions [83]. Taken together, these lines of evidence strongly suggest that BDNF-7 may be rapidly translated in the dendritic compartment upon synaptic activation and that reduction of BDNF-7 levels induced by SI stress may contribute to the behavioral impairments observed in SI adult mice.

Our results showing that SI stress decreased the levels of mGluR1 and mGluR2 in the PFC are in line with previous data reporting a significant attenuation in $\mathrm{mGluR}$ function in the PFC of SI reared rats [84]. Remarkably, it has been also reported that chronic unpredictable stress (CUS) reduces mGluR2 expression and that upregulation of mGluR2 reverses the anxious- and depressive-like behaviors caused by CUS $[48,50]$. Furthermore, a possible role of mGluR2 in controlling hyperactivity has been described as well. Systemic mGluR2/3 agonist administration reverses the SI rearing-induced hyperactivity [85]. Moreover, injecting a mGluR2/3 agonist locally into the PFC blocks the amphetamine-induced hyperactivity [86]. Altogether, these data indicate that downregulation of mGluR2 levels in the PFC of SI mice may contribute to the behavioral impairments observed. Although previous studies have reported behavioral and synaptic plasticity deficits in the mGluR1 null mice $[87,88]$ and mGluR1/5 agonist reduced the anxiety-like behaviors of DBA/2 mice [89], the possible role of mGluR1 in the PFC has not been specifically investigated yet. Further studies will be necessary to assess whether the expression of mGluR1 in the PFC contributes to the behavioral changes induced by SI.

We specifically found a reduction of $m$ GluR1 and $\mathrm{mGluR} 2$ in the PFC but not in the HPC. However, since we have analyzed gene expression in the entire HPC, without subdivision of the different regions (dorsal and ventral hippocampus, dentate gyrus, CA1, and CA3), it is possible that variations in specific regions may be attenuated from the expression in the other regions and therefore not detected by our analyses. Further studies will be necessary to uncover whether changes of the mGluR1 and mGluR2 expression in specific regions of the HPC are actually induced by social isolation. Nevertheless, differential modulation of gene expression in different brain areas is quite common and it has been described for several genes and environmental manipulations.

A major limitation of the present study is the descriptive nature of our analysis. Although we have found significant correlations between behavioral impairments, CORT plasma levels, and gene expression levels in the HPC and PFC, these findings are not sufficient to clearly establish a direct causal effect between these molecular changes and the behavioral alterations. Further studies using both molecular and pharmacological approaches, to specifically modulate the expression of these genes in HPC and PFC, will be necessary. Another limitation of the study is the lack on of time-dependent effects of SI. We have found behavioral and molecular changes after 4 weeks of social isolation stress. It would be interesting in future studies to investigate the shortest period of SI that is able to induce behavioral and molecular changes in adult mice and whether a longer period of isolation is able to worsen the phenotype that we have reported here. Moreover, while we cannot rule out that the molecular changes observed in SI mice are a consequence of the combination of the social isolation paradigm and the behavioral tests, our results show that neuroplasticity-related genes are differentially modulated in GH and SI mice.

Overall, in the present study we showed that SI stress in the adult male mice resulted in anxiety- and depressionlike phenotypes. Additionally, we showed that behavioral modifications correlated with decrease of plasma CORT levels and downregulation of neuroplasticity-related genes in HPC and PFC. In particular, the selective reduction of the BDNF-7 transcript in both brain areas of SI mice for the first time links this dendrite-resident BDNF isoform with synaptic plasticity and the behavioral consequences of SI. 
Further work to explore the role of this BDNF transcript is warranted.

\section{Conflict of Interests}

The authors declare that there is no conflict of interests regarding the publication of this paper.

\section{Acknowledgments}

This work was supported by a grant from MIUR (PRIN 2010 prot. 2010N8PBAA_004) to Maurizio Popoli and is part of the collaborative consortium "Italian Network on BDNF" (InBDNF).

\section{References}

[1] E. R. de Kloet, M. Joëls, and F. Holsboer, "Stress and the brain: from adaptation to disease," Nature Reviews Neuroscience, vol. 6, no. 6, pp. 463-475, 2005.

[2] B. Leuner and T. J. Shors, "Stress, anxiety, and dendritic spines: what are the connections?" Neuroscience, vol. 251, pp. 108-119, 2013.

[3] M. Popoli, Z. Yan, B. S. McEwen, and G. Sanacora, "The stressed synapse: the impact of stress and glucocorticoids on glutamate transmission," Nature Reviews Neuroscience, vol. 13, no. 1, pp. 22-37, 2012.

[4] P. W. Gold, "The organization of the stress system and its dysregulation in depressive illness," Molecular Psychiatry, vol. 20, no. 1, pp. 32-47, 2015.

[5] C. Tsigos and G. P. Chrousos, "Hypothalamic-pituitary-adrenal axis, neuroendocrine factors and stress," Journal of Psychosomatic Research, vol. 53, no. 4, pp. 865-871, 2002.

[6] C. M. Pariante and S. L. Lightman, "The HPA axis in major depression: classical theories and new developments," Trends in Neurosciences, vol. 31, no. 9, pp. 464-468, 2008.

[7] A. Shea, C. Walsh, H. MacMillan, and M. Steiner, "Child maltreatment and HPA axis dysregulation: relationship to major depressive disorder and post traumatic stress disorder in females," Psychoneuroendocrinology, vol. 30, no. 2, pp. 162-178, 2005.

[8] V. Krishnan and E. J. Nestler, "Animal models of depression: molecular perspectives," Current Topics in Behavioral Neurosciences, vol. 7, no. 1, pp. 121-147, 2011.

[9] I. Toth and I. D. Neumann, "Animal models of social avoidance and social fear," Cell and Tissue Research, vol. 354, no. 1, pp. 107118, 2013.

[10] S. Chiba, T. Numakawa, M. Ninomiya, M. C. Richards, C. Wakabayashi, and H. Kunugi, "Chronic restraint stress causes anxiety- and depression-like behaviors, downregulates glucocorticoid receptor expression, and attenuates glutamate release induced by brain-derived neurotrophic factor in the prefrontal cortex," Progress in Neuro-Psychopharmacology and Biological Psychiatry, vol. 39, no. 1, pp. 112-119, 2012.

[11] B. S. McEwen, C. Nasca, and J. D. Gray, "Stress effects on neuronal structure: hippocampus, amygdala, and prefrontal cortex," Neuropsychopharmacology, 2015.

[12] J. F. Cryan and D. A. Slattery, "Animal models of mood disorders: recent developments," Current Opinion in Psychiatry, vol. 20, no. 1, pp. 1-7, 2007.
[13] A. M. Wood, C. J. Boyce, S. C. Moore, and G. D. A. Brown, "An evolutionary based social rank explanation of why low income predicts mental distress: a 17 year cohort study of 30,000 people," Journal of Affective Disorders, vol. 136, no. 3, pp. 882888, 2012.

[14] F. Lederbogen, P. Kirsch, L. Haddad et al., "City living and urban upbringing affect neural social stress processing in humans," Nature, vol. 474, no. 7352, pp. 498-501, 2011.

[15] K. Björkqvist, "Social defeat as a stressor in humans," Physiology and Behavior, vol. 73, no. 3, pp. 435-442, 2001.

[16] L. M. Heinrich and E. Gullone, "The clinical significance of loneliness: a literature review," Clinical Psychology Review, vol. 26, no. 6, pp. 695-718, 2006.

[17] O. Berton, H. E. Covington III, K. Ebner et al., "Induction of deltaFosB in the periaqueductal gray by stress promotes active coping responses," Neuron, vol. 55, no. 2, pp. 289-300, 2007.

[18] H. Dadomo, V. Sanghez, L. Di Cristo et al., "Vulnerability to chronic subordination stress-induced depression-like disorders in adult 129SvEv male mice," Progress in NeuroPsychopharmacology and Biological Psychiatry, vol. 35, no. 6, pp. 1461-1471, 2011.

[19] D. A. Slattery, N. Uschold, M. Magoni et al., "Behavioural consequences of two chronic psychosocial stress paradigms: anxiety without depression," Psychoneuroendocrinology, vol. 37, no. 5, pp. 702-714, 2012.

[20] F. Chaouloff, "Social stress models in depression research: what do they tell us?" Cell and Tissue Research, vol. 354, no. 1, pp. 179190, 2013.

[21] A. Berry, V. Bellisario, S. Capoccia et al., "Social deprivation stress is a triggering factor for the emergence of anxiety- and depression-like behaviours and leads to reduced brain BDNF levels in C57BL/6J mice," Psychoneuroendocrinology, vol. 37, no. 6, pp. 762-772, 2012.

[22] A. Djordjevic, J. Djordjevic, I. Elaković, M. Adzic, G. Matić, and M. B. Radojcic, "Fluoxetine affects hippocampal plasticity, apoptosis and depressive-like behavior of chronically isolated rats," Progress in Neuro-Psychopharmacology and Biological Psychiatry, vol. 36, no. 1, pp. 92-100, 2012.

[23] F. Pibiri, M. Nelson, A. Guidotti, E. Costa, and G. Pinna, "Decreased corticolimbic allopregnanolone expression during social isolation enhances contextual fear: a model relevant for posttraumatic stress disorder," Proceedings of the National Academy of Sciences of the United States of America, vol. 105, no. 14, pp. 5567-5572, 2008.

[24] H. Koike, D. Ibi, H. Mizoguchi et al., "Behavioral abnormality and pharmacologic response in social isolation-reared mice," Behavioural Brain Research, vol. 202, no. 1, pp. 114-121, 2009.

[25] K. C. F. Fone and M. V. Porkess, "Behavioural and neurochemical effects of post-weaning social isolation in rodents-relevance to developmental neuropsychiatric disorders," Neuroscience and Biobehavioral Reviews, vol. 32, no. 6, pp. 1087-1102, 2008.

[26] D. L. Wallace, M.-H. Han, D. L. Graham et al., "CREB regulation of nucleus accumbens excitability mediates social isolationinduced behavioral deficits," Nature Neuroscience, vol. 12, no. 2, pp. 200-209, 2009.

[27] A. Thorsell, C. J. Slawecki, A. El Khoury, A. A. Mathe, and C. L. Ehlers, "The effects of social isolation on neuropeptide Y levels, exploratory and anxiety-related behaviors in rats," Pharmacology Biochemistry and Behavior, vol. 83, no. 1, pp. 2834,2006 
[28] S. Morley-Fletcher, J. Mairesse, A. Soumier et al., "Chronic agomelatine treatment corrects behavioral, cellular, and biochemical abnormalities induced by prenatal stress in rats," Psychopharmacology, vol. 217, no. 3, pp. 301-313, 2011.

[29] J. D. Gray, T. A. Milner, and B. S. McEwen, "Dynamic plasticity: the role of glucocorticoids, brain-derived neurotrophic factor and other trophic factors," Neuroscience, vol. 239, pp. 214-227, 2013.

[30] N. Elizalde, P. M. Pastor, Á. L. Garcia-García et al., "Regulation of markers of synaptic function in mouse models of depression: chronic mild stress and decreased expression of VGLUT1," Journal of Neurochemistry, vol. 114, no. 5, pp. 1302-1314, 2010.

[31] H. D. Schmidt and R. S. Duman, "Peripheral BDNF produces antidepressant-like effects in cellular and behavioral models," Neuropsychopharmacology, vol. 35, no. 12, pp. 2378-2391, 2010.

[32] K. G. Bath, A. Schilit, and F. S. Lee, "Stress effects on BDNF expression: effects of age, sex, and form of stress," Neuroscience, vol. 239, pp. 149-156, 2013.

[33] I. Ninan, "Synaptic regulation of affective behaviors; Role of BDNF, Neuropharmacology C, vol. 76, pp. 684-695, 2014.

[34] R. S. Duman and L. M. Monteggia, "A neurotrophic model for stress-related mood disorders," Biological Psychiatry, vol. 59, no. 12, pp. 1116-1127, 2006.

[35] A. Ieraci, A. Mallei, L. Musazzi, and M. Popoli, "Physical exercise and acute restraint stress differentially modulate hippocampal brain-derived neurotrophic factor transcripts and epigenetic mechanisms in mice," Hippocampus, vol. 25, no. 11, pp. 1380-1392, 2015.

[36] A. Mallei, G. Baj, A. Ieraci et al., "Expression and dendritic trafficking of BDNF-6 splice variant are impaired in knockin mice carrying human BDNF Val66Met polymorphism," International Journal of Neuropsychopharmacology, 2015.

[37] T. Aid, A. Kazantseva, M. Piirsoo, K. Palm, and T. Timmusk, "Mouse and rat BDNF gene structure and expression revisited," Journal of Neuroscience Research, vol. 85, no. 3, pp. 525-535, 2007.

[38] M. R. Lyons and A. E. West, "Mechanisms of specificity in neuronal activity-regulated gene transcription," Progress in Neurobiology, vol. 94, no. 3, pp. 259-295, 2011.

[39] G. Baj, V. D’Alessandro, L. Musazzi et al., "Physical exercise and antidepressants enhance BDNF targeting in hippocampal CA3 dendrites: further evidence of a spatial code for BDNF splice variants," Neuropsychopharmacology, vol. 37, no. 7, pp. 16001611, 2012.

[40] L. Musazzi, J. M. Rimland, A. Ieraci, G. Racagni, E. Domenici, and M. Popoli, "Pharmacological characterization of BDNF promoters I, II and IV reveals that serotonin and norepinephrine input is sufficient for transcription activation," International Journal of Neuropsychopharmacology, vol. 17, no. 5, pp. 779-791, 2014.

[41] M. S. Zajac, T. Y. C. Pang, N. Wong et al., "Wheel running and environmental enrichment differentially modify exonspecific BDNF expression in the hippocampus of wild-type and pre-motor symptomatic male and female Huntington's disease mice," Hippocampus, vol. 20, no. 5, pp. 621-636, 2010.

[42] A. Ieraci and D. G. Herrera, "Nicotinamide protects against ethanol-induced apoptotic neurodegeneration in the developing mouse brain," PLoS Medicine, vol. 3, no. 4, pp. 547-557, 2006.

[43] L. Steru, R. Chermat, B. Thierry, and P. Simon, "The tail suspension test: a new method for screening antidepressants in mice," Psychopharmacology, vol. 85, no. 3, pp. 367-370, 1985.
[44] F. Rusconi, L. Paganini, D. Braida et al., "LSD1 neurospecific alternative splicing controls neuronal excitability in mouse models of epilepsy," Cerebral Cortex, vol. 25, no. 9, pp. 27292740, 2015.

[45] A. Ieraci, P. E. Forni, and C. Ponzetto, "Viable hypomorphic signaling mutant of the met receptor reveals a role for hepatocyte growth factor in postnatal cerebellar development," Proceedings of the National Academy of Sciences of the United States of America, vol. 99, no. 23, pp. 15200-15205, 2002.

[46] S. K. Droste, A. Gesing, S. Ulbricht, M. B. Müller, A. C. E. Linthorst, and J. M. H. M. Reul, "Effects of long-term voluntary exercise on the mouse hypothalamic-pituitary-adrenocortical axis," Endocrinology, vol. 144, no. 7, pp. 3012-3023, 2003.

[47] I. Gerendai and B. Halász, "Neuroendocrine asymmetry," Frontiers in Neuroendocrinology, vol. 18, no. 3, pp. 354-381, 1997.

[48] B. Cuccurazzu, V. Bortolotto, M. M. Valente et al., "Upregulation of mGlu2 receptors via NF- $\kappa$ B p65 acetylation is involved in the proneurogenic and antidepressant effects of acetyl-Lcarnitine," Neuropsychopharmacology, vol. 38, no. 11, pp. 2220 2230, 2013.

[49] B. H. Harvey and M. Shahid, "Metabotropic and ionotropic glutamate receptors as neurobiological targets in anxiety and stress-related disorders: Focus on pharmacology and preclinical translational models," Pharmacology Biochemistry and Behavior, vol. 100, no. 4, pp. 775-800, 2012.

[50] C. Nasca, B. Bigio, D. Zelli, F. Nicoletti, and B. S. McEwen, "Mind the gap: glucocorticoids modulate hippocampal glutamate tone underlying individual differences in stress susceptibility," Molecular Psychiatry, vol. 20, no. 6, pp. 755-763, 2015.

[51] S. Kubik, T. Miyashita, and J. F. Guzowski, "Using immediateearly genes to map hippocampal subregional functions," Learning \& Memory, vol. 14, no. 11, pp. 758-770, 2007.

[52] J. B. Levine, R. M. Youngs, M. L. MacDonald et al., "Isolation rearing and hyperlocomotion are associated with reduced immediate early gene expression levels in the medial prefrontal cortex," Neuroscience, vol. 145, no. 1, pp. 42-55, 2007.

[53] R. Okada, K. Matsumoto, R. Tsushima, H. Fujiwara, and K. Tsuneyama, "Social isolation stress-induced fear memory deficit is mediated by down-regulated neuro-signaling system and Egr-1 expression in the brain," Neurochemical Research, vol. 39, no. 5, pp. 875-882, 2014.

[54] Q. Pei, T. S. C. Zetterström, M. Sprakes, R. Tordera, and T. Sharp, "Antidepressant drug treatment induces Arc gene expression in the rat brain," Neuroscience, vol. 121, no. 4, pp. 975-982, 2003.

[55] A. Djordjevic, M. Adzic, J. Djordjevic, and M. B. Radojcic, "Stress type dependence of expression and cytoplasmic-nuclear partitioning of glucocorticoid receptor, Hsp90 and Hsp70 in Wistar rat brain," Neuropsychobiology, vol. 59, no. 4, pp. 213-221, 2009.

[56] A. L. Martin and R. E. Brown, "The lonely mouse: verification of a separation-induced model of depression in female mice," Behavioural Brain Research, vol. 207, no. 1, pp. 196-207, 2010.

[57] A. Bartolomucci, P. Palanza, P. Sacerdote et al., "Individual housing induces altered immuno-endocrine responses to psychological stress in male mice," Psychoneuroendocrinology, vol. 28, no. 4, pp. 540-558, 2003.

[58] X. Liu, R. Wu, F. Tai et al., "Effects of group housing on stress induced emotional and neuroendocrine alterations," Brain Research, vol. 1502, pp. 71-80, 2013.

[59] B. M. M. Monteiro, F. A. Moreira, A. R. Massensini, M. F. D. Moraes, and G. S. Pereira, "Enriched environment increases 
neurogenesis and improves social memory persistence in socially isolated adult mice," Hippocampus, vol. 24, no. 2, pp. 239-248, 2014.

[60] H. Ito, M. Nagano, H. Suzuki, and T. Murakoshi, "Chronic stress enhances synaptic plasticity due to disinhibition in the anterior cingulate cortex and induces hyper-locomotion in mice," Neuropharmacology, vol. 58, no. 4-5, pp. 746-757, 2010.

[61] M. Kabbaj, D. P. Devine, V. R. Savage, and H. Akil, "Neurobiological correlates of individual differences in novelty-seeking behavior in the rat: differential expression of stress-related molecules," The Journal of Neuroscience, vol. 20, no. 18, pp. 69836988, 2000.

[62] V. Võikar, A. Polus, E. Vasar, and H. Rauvala, "Long-term individual housing in C57BL/6J and DBA/2 mice: assessment of behavioral consequences," Genes, Brain and Behavior, vol. 4, no. 4, pp. 240-252, 2005.

[63] A. Zimprich, L. Garrett, J. M. Deussing et al., "A robust and reliable non-invasive test for stress responsivity in mice," Frontiers in Behavioral Neuroscience, vol. 8, article 125, 2014.

[64] G. Beitia, L. Garmendia, A. Azpiroz, O. Vegas, P. F. Brain, and A. Arregi, "Time-dependent behavioral, neurochemical, and immune consequences of repeated experiences of social defeat stress in male mice and the ameliorative effects of fluoxetine," Brain, Behavior, and Immunity, vol. 19, no. 6, pp. 530-539, 2005.

[65] L. M. Bierer, L. Tischler, E. Labinsky, S. Cahill, E. Foa, and R. Yehuda, "Clinical correlates of 24-h cortisol and norepinephrine excretion among subjects seeking treatment following the World Trade Center attacks on 9/11," Annals of the New York Academy of Sciences, vol. 1071, pp. 514-520, 2006.

[66] D. Hauer, F. Weis, T. Krauseneck, M. Vogeser, G. Schelling, and B. Roozendaal, "Traumatic memories, post-traumatic stress disorder and serum cortisol levels in long-term survivors of the acute respiratory distress syndrome," Brain Research, vol. 1293, pp. 114-120, 2009.

[67] T. C. Neylan, A. Brunet, N. Pole et al., "PTSD symptoms predict waking salivary cortisol levels in police officers," Psychoneuroendocrinology, vol. 30, no. 4, pp. 373-381, 2005.

[68] D. L. Delahanty, A. J. Raimonde, and E. Spoonster, "Initial posttraumatic urinary cortisol levels predict subsequent PTSD symptoms in motor vehicle accident victims," Biological Psychiatry, vol. 48, no. 9, pp. 940-947, 2000.

[69] C. Heim, U. Ehlert, and D. H. Hellhammer, "The potential role of hypocortisolism in the pathophysiology of stress-related bodily disorders," Psychoneuroendocrinology, vol. 25, no. 1, pp. $1-35,2000$.

[70] R. Reznikov, M. Diwan, J. N. Nobrega, and C. Hamani, "Towards a better preclinical model of PTSD: characterizing animals with weak extinction, maladaptive stress responses and low plasma corticosterone," Journal of Psychiatric Research, vol. 61, pp. 158-165, 2015.

[71] K. Matsumoto, K. Ono, H. Ouchi, R. Tsushima, and Y. Murakami, "Social isolation stress down-regulates cortical early growth response 1 (Egr-1) expression in mice," Neuroscience Research, vol. 73, no. 3, pp. 257-262, 2012.

[72] M. G. Pisu, R. Dore, M. C. Mostallino et al., "Down-regulation of hippocampal BDNF and Arc associated with improvement in aversive spatial memory performance in socially isolated rats," Behavioural Brain Research, vol. 222, no. 1, pp. 73-80, 2011.

[73] O. Steward, S. Farris, P. S. Pirbhoy, J. Darnell, and S. J. Van Driesche, "Localization and local translation of Arc/Arg3.1 mRNA at synapses: some observations and paradoxes," Frontiers in Molecular Neuroscience, vol. 7, article 101, 2015.
[74] E. Korb and S. Finkbeiner, "Arc in synaptic plasticity: from gene to behavior," Trends in Neurosciences, vol. 34, no. 11, pp. 591-598, 2011.

[75] H. Wang, Y. Z. Zhu, P. T.-H. Wong et al., "cDNA microarray analysis of gene expression in anxious PVG and SD rats after cat-freezing test," Experimental Brain Research, vol. 149, no. 4, pp. 413-421, 2003.

[76] C. R. Bramham, P. F. Worley, M. J. Moore, and J. F. Guzowski, "The immediate early gene Arc/Arg3.1: regulation, mechanisms, and function," The Journal of Neuroscience, vol. 28, no. 46, pp. $11760-11767,2008$.

[77] O. Steward and P. Worley, "Local synthesis of proteins at synaptic sites on dendrites: role in synaptic plasticity and memory consolidation?" Neurobiology of Learning and Memory, vol. 78, no. 3, pp. 508-527, 2002.

[78] J. F. Guzowski, B. Setlow, E. K. Wagner, and J. L. McGaugh, "Experience-dependent gene expression in the rat hippocampus after spatial learning: a comparison of the immediate-early genes Arc, c-fos, and zif268," The Journal of Neuroscience, vol. 21, no. 14, pp. 5089-5098, 2001.

[79] M. W. Jones, M. L. Errington, P. J. French et al., "A requirement for the immediate early gene Zif268 in the expression of late LTP and long-term memories," Nature Neuroscience, vol. 4, no. 3, pp. 289-296, 2001.

[80] L. Li, J. Carter, X. Gao, J. Whitehead, and W. G. Tourtellotte, "The neuroplasticity-associated arc gene is a direct transcriptional target of early growth response (Egr) transcription factors," Molecular and Cellular Biology, vol. 25, no. 23, pp. 10286-10300, 2005.

[81] V. Vaghi, A. Polacchini, G. Baj, V. L. M. Pinheiro, A. Vicario, and E. Tongiorgi, "Pharmacological profile of brain-derived neurotrophic factor (BDNF) splice variant translation using a novel drug screening assay: a 'quantitative code,' The Journal of Biological Chemistry, vol. 289, no. 40, pp. 27702-27713, 2014.

[82] G. Baj, D. Del Turco, J. Schlaudraff, L. Torelli, T. Deller, and E. Tongiorgi, "Regulation of the spatial code for BDNF mRNA isoforms in the rat hippocampus following pilocarpinetreatment: A systematic analysis using laser microdissection and quantitative real-time PCR," Hippocampus, vol. 23, no. 5, pp. 413-423, 2013.

[83] C. Verpelli, G. Piccoli, A. Zanchi et al., "Synaptic activity controls dendritic spine morphology by modulating eEF2dependent BDNF synthesis," Journal of Neuroscience, vol. 30, no. 17, pp. 5830-5842, 2010.

[84] R. I. Melendez, M. L. Gregory, M. T. Bardo, and P. W. Kalivas, "Impoverished rearing environment alters metabotropic glutamate receptor expression and function in the prefrontal cortex," Neuropsychopharmacology, vol. 29, no. 11, pp. 1980-1987, 2004.

[85] Y. Ago, R. Araki, K. Yano et al., "The selective metabotropic glutamate 2/3 receptor agonist MGS0028 reverses isolation rearing-induced abnormal behaviors in mice," Journal of Pharmacological Sciences, vol. 118, no. 2, pp. 295-298, 2012.

[86] Y. Ago, R. Araki, K. Yano et al., "Activation of metabotropic glutamate $2 / 3$ receptors attenuates methamphetamine-induced hyperlocomotion and increase in prefrontal serotonergic neurotransmission," Psychopharmacology, vol. 217, no. 3, pp. 443452, 2011.

[87] F. Conquet, Z. I. Bashir, C. H. Davies et al., "Motor deficit and impairment of synaptic plasticity in mice lacking mGluR1," Nature, vol. 372, no. 6503, pp. 237-243, 1994.

[88] C. Gil-Sanz, J. M. Delgado-García, A. Fairén, and A. Gruart, "Involvement of the mGluR1 receptor in hippocampal synaptic 
plasticity and associative learning in behaving mice," Cerebral Cortex, vol. 18, no. 7, pp. 1653-1663, 2008.

[89] F. Zhang, B. Liu, Z. Lei, and J.-H. Wang, "MGluR1,5 activation improves network asynchrony and GABAergic synapse attenuation in the amygdala: implication for anxiety-like behavior in DBA/2 mice," Molecular Brain, vol. 5, article 20, 2012. 

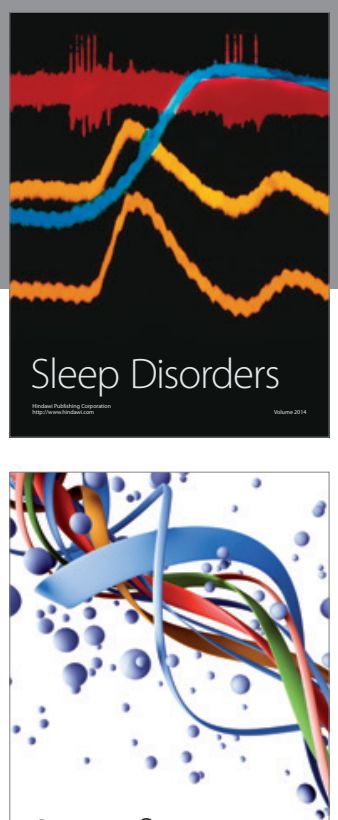

Scientifica
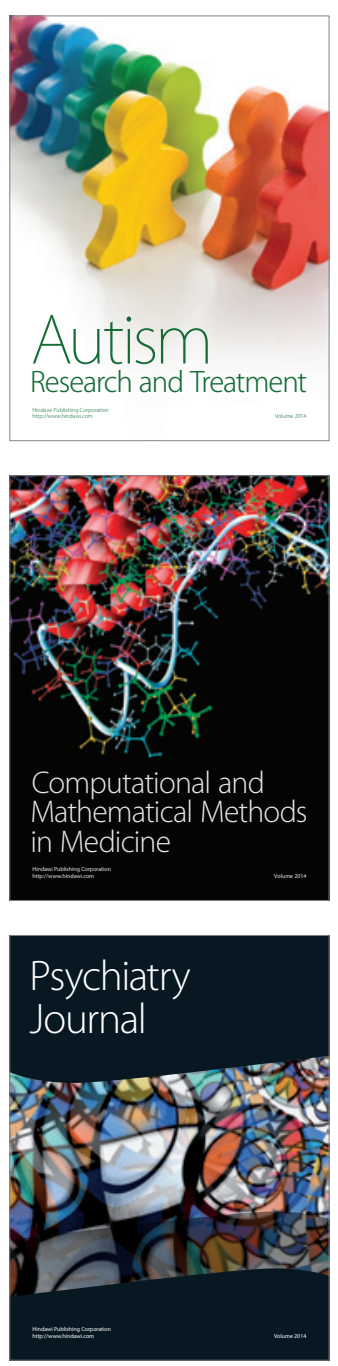
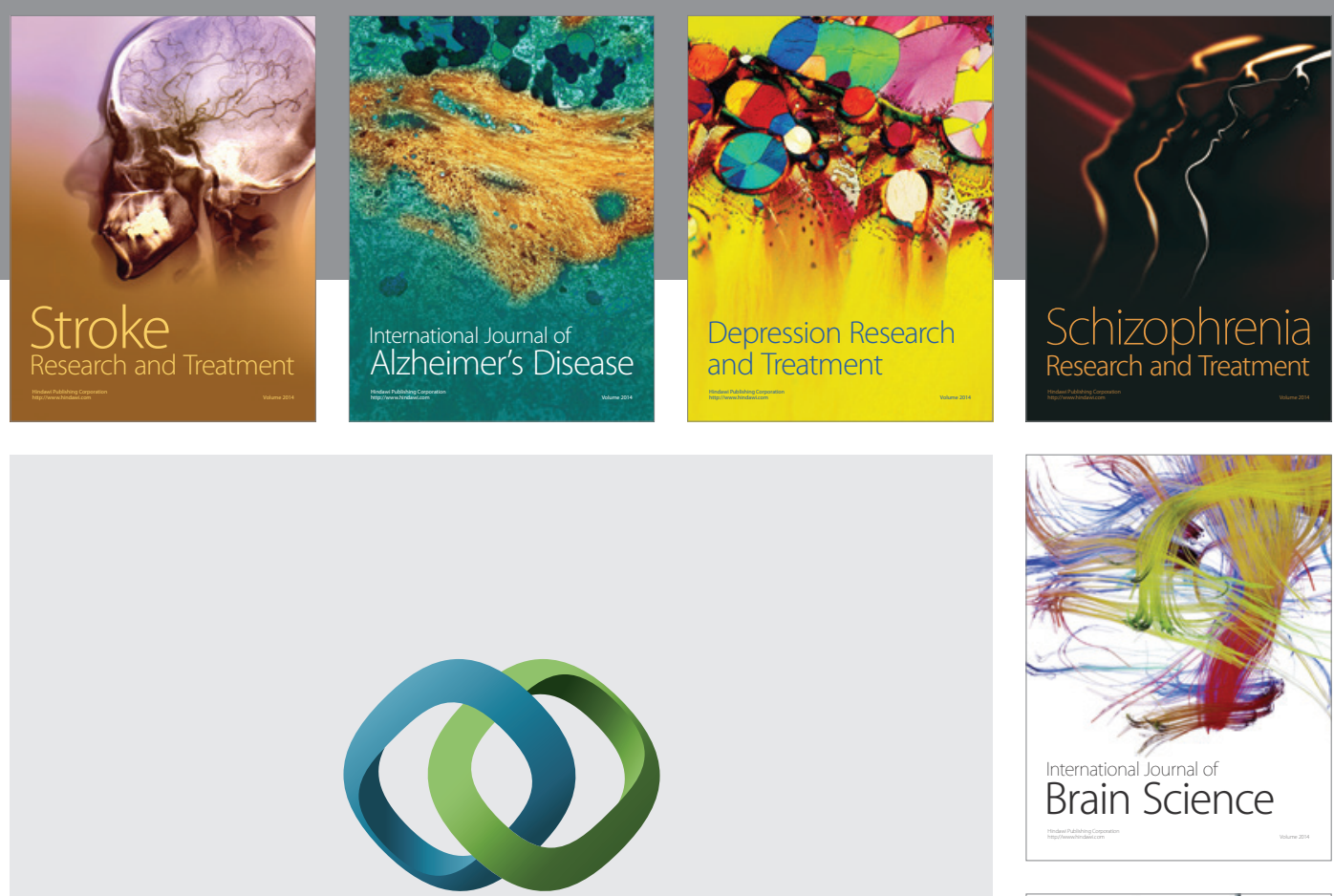

\section{Hindawi}

Submit your manuscripts at

http://www.hindawi.com
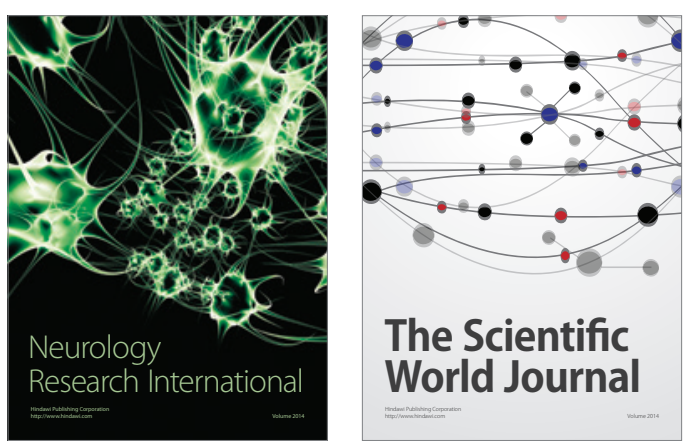

The Scientific World Journal

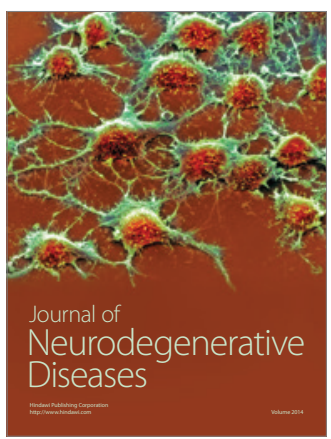

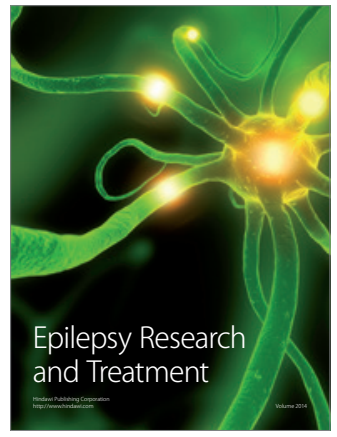

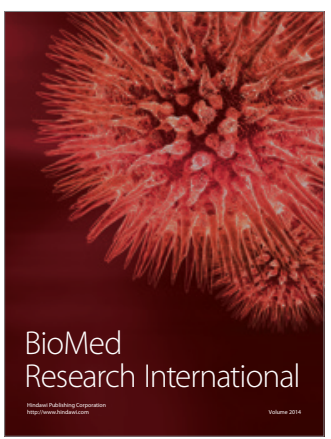

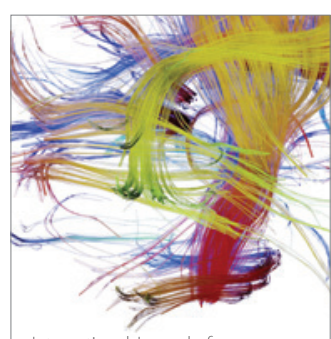

Brain Science

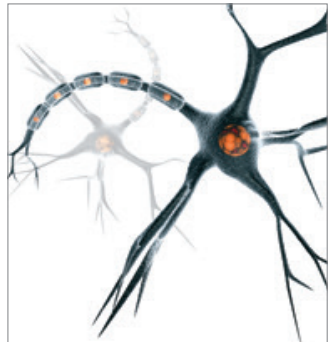

Neural Plasticity
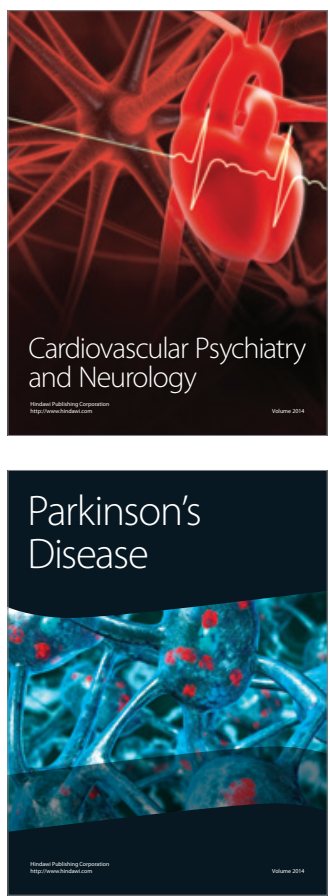